one. It rejects theoretical reductionism and, as a consequence, is hesitant to adopt the methodological reductionism required by standardised evidencebased approaches. Many French psychiatrists consider that this type of approach is an artefact and does not account for psychiatric subjective reality. The same sort of ambivalence appears when one looks at nosographic issues: most French psychiatrists consider

Most French

psychiatrists

consider

DSM-IV to be a

purely research

classification that is inadequate for clinical work, and which therefore serves to increase the split between research and clinical reality.
DSM-IV to be a purely research classification that is inadequate for clinical work, and which therefore serves to increase the split between research and clinical reality.

French psychiatry is relatively under-resourced in terms of research. There is no specific research institute in psychiatry comparable to the Institute of Psychiatry in London. There are twice as many researchers at the Institute of Psychiatry as there are in all of France, despite the density of psychiatrists being, nationally, four times higher.

Epidemiological and outcome studies as well as aetiological research are thus relatively rare in all psychiatric fields. However, things are changing, with young psychiatrists placing a growing value on publication in international journals with a high impact factor (i.e. in English-language journals) for academic advancement. Genetic and cognitive work on schizophrenia, autism, eating disorders, bipolar disorders and borderline personality disorders is currently emerging but has yet to be published.

The abundant French-language literature contains valuable theoretical and clinical work on infant and adolescent mental health, bridges with social sciences, attachment and separation theory, developmental approaches in work with children and adolescents, the therapeutic alliance and community treatments. Much of this work adopts a psychodynamic perspective and refers to psychoanalytic or phenomenological psychopathology. Current leading topics are psychodynamic and cognitive approaches to schizophrenia and borderline personality disorders, and psychodynamic and systemic approaches to addiction, eating disorders and infant-mother interactions.

\section{Professional organisations}

Another specific feature of French psychiatry is that there is a division between psychiatric scientific organisations and the professional 'syndicate' bodies. Another uncommon feature is the number of these organisations. French psychiatry has nearly 40 active scientific associations and six specific syndicates. Syndicates are related to different types of practice, whereas the scientific associations were established on the basis of theoretical differences or are closely linked with one of the syndicates. The associations are of unequal importance: some have fewer than 100 members, whereas the larger ones have nearer 2000; some are of historical or symbolic value, but others are directly dependent on a syndicate; some issue a journal whereas others do not; some have only an annual scientific meeting, whereas others have monthly business or scientific meetings. None the less, all of them are federated on an equal basis in the French Federation of Psychiatry (FFP), which was created 10 years ago to try to overcome the weakness of such divided psychiatric scientific representation. International representation is still quite scattered, however. Six of the French scientific associations are members of the World Psychiatric Association (WPA) - the French Association of Psychiatry, the Psychiatric Evolution Society, the Medico-Psychological Society, the French Association of Psychiatrists of Private Practice, the Psychiatric Information Society (public sector psychiatrists) and the French Society of Expression Psychopathology - but it has been impossible to unify this representation under the FFP banner, and French psychiatrists are still rather under-represented in the WPA, as they are in most international and even European psychiatric societies.

\title{
Earthquake in Pakistan and Kashmir: suggested plan for psychological trauma relief work
}

\author{
M. Akmal Makhdum ${ }^{1}$ and Afzal Javed ${ }^{2}$
}

1103A Valley Road, Ipswich IP1 4PE, Suffolk, UK, email akmal.makhdum@smhp.nhs.uk

${ }^{2}$ Medical Centre, Manor Court Avenue, Nuneaton CV11 5HX, UK, email afzal.javed@ntlworld.com

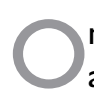
n the morning of 8 October 2005, Pakistan and Pakistani-controlled Kashmir were hit by an earthquake that measured 7.6 on the Richter scale. Within 5 seconds, almost all buildings in two major cities of the north were destroyed: the capital of Pakistani-controlled Kashmir, Muzaffarabad, and Balakot, a picturesque mountain city. This was about 9 a.m. Children were in classrooms and mothers were doing household chores. Many men were in the fields. Therefore, when houses 
and buildings collapsed, thousands of young children and women were killed, as a result of falling roofs and walls. All government buildings, universities and colleges were destroyed and thousands of students died. In one town there were no children left alive: a generation had been wiped out. In two schools alone people were trying to retrieve 600 bodies of young girls. The earthquake hit hardest in difficult mountainous terrain. Even under normal conditions, four-wheel-drive vehicles are required to travel in this area; after the earthquake, landslides had blocked access to large villages. Many small villages were buried.

This whole area, according to the last census, had 3.6 million inhabitants, living in 530000 households. The rural population was 3.3 million and the urban population just over 300000 . Muzaffarabad had a population of 904000 in 125000 households.

It is the 3.3 million rural people who suffered the most. It was difficult to get to them for days. Pakistan did not have enough air transport vehicles to meet the need and asked for international help.

Mass and severe trauma has multiple personal, social and future dimensions which affect social and political stability, in both the short and the long term. These affect communities in many ways and devastate individuals.

Pakistan has had three great traumatic events in the past. Two were direct tragedies, traumatising Pakistan's large rural population. One was a mass social upheaval, the effects of which are still felt in all aspects of Pakistani social life (this is aside from the creation of Pakistan, which was characterised by mass migration, ethnic cleansing and massacres of refugees on the border of India and Pakistan in 1947). These three events in the 1970s were: the flood in (then) East Pakistan, in 1970; a huge earthquake in northern areas in 1973; and the 3 million Afghan refugees who entered Pakistan, traumatised and devastated by Russian invasion and atrocities in their home country.

Such tragedies pose enormous challenges for mental heathcare, but disasters may sometimes be opportunities to develop greatly needed communitybased mental health services in under-resourced regions. It therefore becomes imperative to use the available resources to get services in place.

The current earthquake has many dimensions, some of which are as follows:

o the effect on children, traumatised and left alone, numb with shock

the effect on adults, left alone, grief stricken, numb with trauma

the specific concern about young, adolescent and adult women (women are particularly at risk)

O young and working-age men in need of meaning and purpose (which the trajedy has taken away)

o migrants in search of safety and food (who have effects on the host community; in the short term crime, drugs and prostitution; in the long term there may be a need to tackle resentment)

o how to avoid the tent cities for survivors becoming ghettoes

O vocational and occupational identity crises.

The situation in Pakistan is dire owing to the limited resources. The response therefore needs to be imaginative. Victims need to be treated for emotional and psychological trauma, but this can be done by relatives, friends, teachers and their own community professionals. This has to be a long-term process of community support.

Reports have suggested that there are more than 70000 dead and 60000 seriously injured. As whole remote villages perished without a trace, the true totals may never be known. The numbers of dead and injured are estimated to be at least four times these figures once final statistics are gathered. There are those who are damaged and injured emotionally, after seeing horrible death and destruction. They are not yet counted. These could number hundreds of thousands or more.

The management of disasters like this needs to be tailored to local requirements (World Health Organization, 2003; Van Ommeren et al, 2005; Saraceno, 2005). To address the massive needs and very limited professional resources (as happens in many developing countries), many innovative approaches will have to be considered (Singh \& D'Souza, 2005; World Health Organization, 2005).

\section{Treatment clinics}

Treatment clinics should be run on an individual and group basis, initially under the supervision of registered professionals but in collaboration and participation with local communities (see below). These should be culturally sensitive yet emotionally empowering (e.g. female professionals for female victims, whenever appropriate).

\section{Training programmes}

Experience from other countries, and especially after the tsunami, suggests that self-help and community involvement matter more to people than formal help from trained professionals. The former are more meaningful than the latter, as they are culturally appropriate and empathic. Training is required for community volunteers and community leaders to deliver this help. Those who are less emotionally damaged can provide help to their own community and they then can become helpers rather than victims.

The following groups need to be involved:

O family practitioners, social workers and community workers, to be trained in the management of trauma-related psychological distress

o primary and secondary school, college and university teachers, to be trained in short-term trauma
Victims need to be treated for emotional and psychological trauma, but this can be done by relatives, friends, teachers and their own community professionals.

This has to be a long-term process of community support.

Experience from other countries and especially after the tsunami suggests that self-help and community involvement matter more to people than formal help from trained professionals. 
treatment and management in short training courses

volunteers, trained on brief trauma management courses

O multidisciplinary professionals, to conduct the training.

The training should be modular and based on manuals.

It is important that those who help are also protected by mentoring. If they are to develop into selfhelp communities and local

volunteers are to be trained, then they will be in need of constant help. That should be ensured.
Another important issue is the place of religion, spirituality and religious rituals in enhancing resilience, coping and rebuilding through acceptance and finding some meaning even in suffering and loss. There have been many examples of when type of feeling being empowering.

\section{Governmental liaison - new lives, new cities}

Expert liaison with the government of Pakistan and Kashmir needs to be initiated over social development in view of the emotional state of the communities affected. There needs to be proactive advice on social drift: the risks of drug addiction and misuse, crime, prostitution and so on numbed victims who are untreated can become involved in self-destructive and socially destructive activities).

It is important that new ghettoes are not established in the planned tent cities, that these are only temporary measures and that communities are retained in their structure according to their culture. Graves of parents and ancestors are strong bonds for most people in that area. There is strong attachment to the memory of one's parents in Pakistan and Kashmir. Artificially created communities always develop social problems.

\section{Mentoring and protecting}

It is important that those who help are also protected by mentoring. If they are to develop into self-help communities and local volunteers are to be trained, then they will be in need of constant help. That should be ensured.

To develop as community helpers, the respect and participation of communities are essential. In such times, people need to become protectors of each other, to develop into purposeful individuals and communities.

With such measures in place, services may be able to provide hope to victims and also help local mental health services.

\section{References}

Saraceno, B. (2005) WHO's mental health response to the Asian victims. World Psychiatry, 4, 66-68.

Singh, B. \& D'Souza, R. (2005) Mental health challenges in Sri Lanka from working within the disaster areas. World Psychiatry, 4, 68

Van Ommeren, M., Saxena, S. \& Saraceno, B. (2005) Mental and social health during and after acute emergencies: emerging consensus? WHO Bulletin, 83, 7I-75.

World Health Organization (2003) Mental Health in Emergencies: Psychological and Social Aspects of Health of Populations Exposed to Extreme Stressors. Geneva: WHO.

World Health Organization (2005) Briefing Note on Psychosocial/ Mental Health Assistance to the Tsunami-Affected Region. Geneva: $\mathrm{WHO}$

\section{Senior Volunteers Programme: a visit to Zambia}

\section{Andrew Sims and Ruth Sims}

Church Farm House, Alveley, Bridgnorth, Shropshire WV15 6ND, UK

\section{Of the 12 million population of Zambia, 50\% are aged 15 or younger. Lusaka, the capital, is home to 3 million, most of whom live in single-room dwellings with minimal amenities.}

Coll he Board of International Affairs of the Royal College of Psychiatrists initiated the Senior Volunteers Programme in $\mathbf{2 0 0 4}$ following discussion at the Board and planning in a subgroup over the preceding year. The aim was to match requests from other countries for specific psychiatric teaching with the services of senior psychiatrists in Britain. The College has acted as intermediary, inviting requests from countries, Members and Fellows overseas, and setting up a database of psychiatrists offering a range of skills. The concept is simple but all the skill and hard work lies in the detail!

When preparations for the Senior Volunteer Programme were nearly complete, the planning group wished to carry out a pilot scheme using a volunteer. Mr John Mayeya, Mental Health Specialist of the Central Board of Health, Zambia, with Professor Alan Haworth, an Honorary Fellow of the College and Professor of Psychiatry in Lusaka, invited us to contribute to undergraduate teaching in the Medical School of the University of Zambia, participate in the training programme for mental health clinical officers and have seminars and clinical exchange with junior doctors in psychiatry. We were also invited to discuss mental health services and postgraduate psychiatric education.

Of the 12 million population of Zambia, $50 \%$ are aged 15 or younger. Lusaka, the capital, is home to 